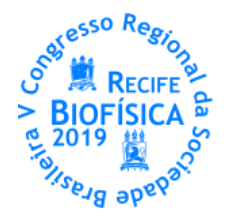

\title{
MICROSCOPIA DE VARREDURA POR SONDA: UMA INTRODUÇÃO À CARACTERIZAÇÃO DAS PROPRIEDADES ULTRAESTRUTURAIS DE SUPERFÍCIE E MAGNÉTICAS DE NANOPARTÍCULAS DE SÍLICA E GRAFENO
}

\author{
Arthur Ferreira $^{1 *}$, Ralph Santos-Oliveira ${ }^{2}$, Francisco Franciné Maia Jr. ${ }^{3}$, Alan Silva de Menezes ${ }^{1}$, Luciana Magalhães \\ Rebelo Alencar ${ }^{1}$
}

${ }^{1}$ Departamento de Física, Universidade Federal do Maranhão - UFMA, São Luis, MA; ${ }^{2}$ Universidade Estadual da Zona Oeste- UEZO, Rio de Janeiro, RJ; 'Departamento de Ciências Naturais, Matemática e Estatística, Universidade Federal do Semi-Árido - UFERSA, Mossoró, RN

*ath.ferreira.af@gmail.com

\section{INTRODUÇÃO}

Desde a construção do primeiro microscópio de força atômica (AFM - Atomic Force Microscopy) em 1986 e o desenvolvimento da técnica por ele utilizada, uma potente ferramenta foi incorporada no estudo das interações de superfícies por meio da análise das curvas de força-distância produzidas por esse equipamento. Os gráficos de força são usados para medir as interações entre a sonda do equipamento e a amostra analisada. Mais recentemente, os microscopistas começaram a esboçar medidas de força através de superfícies inteiras a fim de revelar novas informações sobre a amostra. Esta área da microscopia promete abrir novos tópicos em ciências dos materiais, em biologia e em outras áreas investigativas.

A ideia da microscopia de varredura por sonda é totalmente diversa das demais técnicas de microscopia. Um microscópio de varredura por sonda (SPM - Scanning Probe Microscopy) é um conjunto de instrumentos compostos basicamente de sonda sensora, cerâmicas piezelétricas utilizadas para posicionar a amostra em relação à sonda, circuitos de realimentação para o controle da posição vertical da sonda e um computador para realizar a movimentação dos escâneres de varredura, armazenar os dados extraídos nas medidas e os converter em imagens por meio de um software específico (Fig. 1).

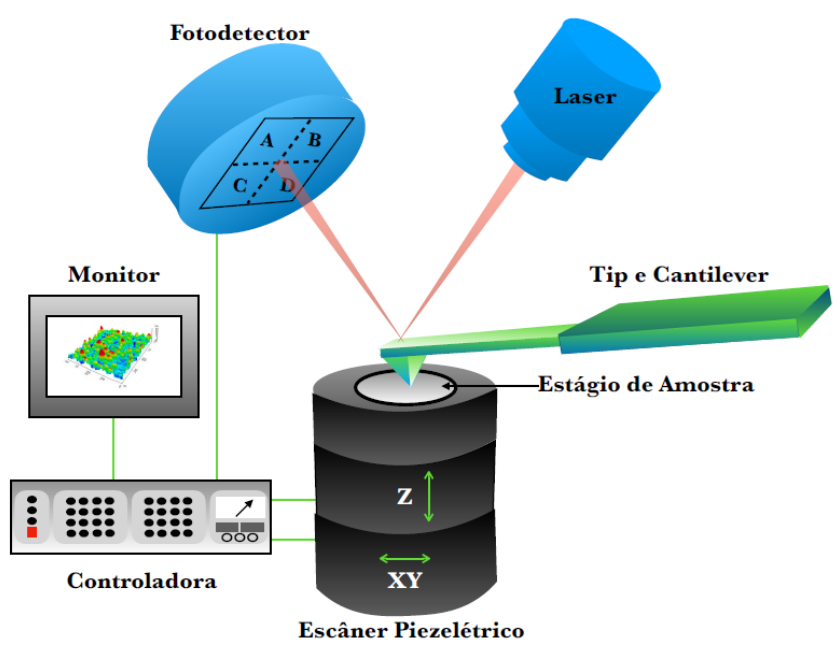

Figura 1. Representação esquemática dos componentes de um microscópio de força atômica. Adaptado de REBELO (2010).
Para se monitorar a interação sonda/amostra, utiliza-se um laser que, ao se refletir na superfície do cantilever, atinge um fotodetector. A variação da posição do laser no fotodetector será utilizada para monitorar as deflexões do cantilever (ocasionadas pelas forças de interação) e para produzir sinais elétricos que serão utilizados no mecanismo de feedback (ZANETTE (2010)). Este mecanismo consiste no processamento, amplificação e produção de sinais elétricos que são utilizados para manter a constância de um determinado parâmetro de referência que esteja relacionado com a interação sonda/amostra.

Para exemplificar seu funcionamento, suponha que o parâmetro de referência seja uma determinada deflexão do cantilever. À medida em que a sonda varre a amostra, interagindo com a mesma em pontos distintos, as forças de interação podem sofrer modificações que acarretam mudanças na deflexão de referência do cantilever. Quando isso ocorre, o laser refletido atingirá o fotodetector em uma posição diferente da que incidia antes. Essa variação indicará ao feedback que o parâmetro de referência está modificado, ou seja, que a interação sonda/amostra foi alterada.

Se essa interação depender da distância (o que geralmente ocorre), o mecanismo de feedback produzirá um sinal elétrico que intervirá no escâner, fazendo com que este modifique a distância de separação entre a sonda e a amostra para que a deflexão de referência seja reestabelecida. Assim, o feedback detecta as mudanças na deflexão de referência e faz uma intervenção no sistema para que o parâmetro de referência volte ao seu valor original. É nessa intervenção que se extrai o dado topográfico e outras propriedades da amostra.

Há três formas de se promover a interação sonda/amostra para a obtenção de imagens e de outras propriedades (modos de operação): o modo contato, também conhecido como contact mode ou dc mode, o modo de contato intermitente ou periódico (tapping mode) e o modo de não-contato.

No modo contato, a ponta está fisicamente em contato com a superfície da amostra enquanto a mesma é varrida. A força de interação é repulsiva e é possível obter imagens com maior rapidez sem perda de resolução. Executado em ar (condições ambientais do laboratório) ou em meio líquido, esse modo fornece além de imagens topográficas, informações sobre as forças laterais (atrito) e as normais, de curto e longo alcance, que atuam na interação. $\mathrm{Em}$ ar, a ponta fica parcialmente imersa em uma camada de fluido adsorvida sobre a superfície da amostra (camada de contaminação). Essa camada contribui para ação de forças de 
capilaridade que aumentam a força exercida pela ponta sobre a amostra, podendo prejudicar a análise e danificar a amostra. No entanto, tais forças podem ser eliminadas empregando-se o modo contato em um meio líquido, onde a ponta e a amostra estão totalmente imersas (V. J. MORRIS (2009)).

No modo contato intermitente, em ar, a ponta varre a amostra fazendo contatos intermitentes enquanto oscila sobre a mesma, evitando assim, uma longa permanência na camada de contaminação. Nesse caso, utilizam-se forças atrativas de longo alcance para se monitorar a interação sonda/amostra. As vantagens no uso do modo intermitente são: a eliminação de forças laterais na detecção, a alta resolução lateral sobre muitos tipos de amostra e a utilização de forças com baixa intensidade, preservando a integridade da amostra durante a obtenção de imagens. Além de topografia, o modo tapping pode ser utilizado para a obtenção de imagens que revelam propriedades elétricas e magnéticas de materiais. A desvantagem na aplicação desse modo de operação deve-se à baixa velocidade de varredura (V. J. MORRIS (2009)).

Já no modo não-contato, a tip oscila próximo à superfície da amostra sem tocá-la, ficando acima da camada de contaminação e interagindo com as forças de van der Waals que se estendem até 10 $\mathrm{nm}$ acima desta camada. Essas forças de interação são relativamente mais baixas, o que ocasiona uma baixa resolução lateral (condicionada pela distância sonda/amostra) e consequente limitação desse modo (V. J. MORRIS (2009)).

A resolução vertical da técnica de AFM operando em ar é de aproximadamente 0.1-0.5 nm, enquanto na horizontal é de 1-5 nm, dependendo da rigidez da amostra. A resolução horizontal sobre a superfície de células vivas, em líquidos, tende a diminuir para algumas dezenas de nanômetros devido a "maciez" da superfície da membrana (KUZNETSOVA T. G. (2007)), dificultando o processo de medida topográfica. Segundo ALESSANDRINI \& FACCI (2005), a sensibilidade e a resolução da técnica também dependem das características da tip e do cantilever (por exemplo, raio, formato, material e etc.).

As técnicas de varredura por sonda alargaram nosso conhecimento dentro dos "mundos" nano e micrométrico. Ademais, "tocar" os objetos é um pré-requisito essencial para manipulá-los. Essa habilidade em sentir moléculas e átomos é, certamente, um marco revolucionário na microscopia. As escalas de trabalho do AFM podem variar de $100 \mu \mathrm{m}$, o que permite analisar algumas células vivas, macromoléculas e algumas bactérias, e podendo chegar, com boas resoluções, na faixa de até $5 \mathrm{~nm}$, o que permite a análise morfológica de vírus, nanopartículas e algumas biomoléculas. Além de produzir imagens topográficas, o AFM também é capaz de investigar as propriedades mecânicas e outros atributos fundamentais para muitas amostras, tais como aderência e elasticidade locais, interações de forças magnéticas e eletrostáticas.

A adesão microscópica influencia uma grande variedade de eventos, desde o comportamento de cerâmicas e materiais compostos até a replicação de DNA e atuação de drogas no corpo humano (C. B. PRATER (1995)). Propriedades elásticas possuem uma importância similar, afetando frequentemente a estrutura e dinâmica de sistemas, num universo que abrange diversos materiais compostos.

Na Fig. 2, temos um gráfico de uma curva mostrando o movimento da sonda. 0 eixo horizontal traça o movimento da sonda referente à amostra. Enquanto a sonda desce para a amostra, a distância sonda/amostra diminui. A deflexão do cantilever é traçada no eixo vertical do mesmo gráfico, o que revela pelo menos dois fatos muito importantes.

O primeiro é a atração sonda/amostra. Quando a ponta se aproxima da amostra, várias forças atrativas atuam sobre ela.
Nota-se que a sonda, de repente, "mergulha" em direção à amostra durante a descida. Isto é comumente chamado de "pulo ao contato", e é devido, geralmente, às forças da atração eletrostática e ou tensão superficial (capilaridade). A atração é também evidente onde o cantilever é empurrado para longe da amostra. Se as forças atrativas forem fortes o bastante, a ponta aderir-se-á à superfície da amostra. Quando a sonda se desprende da superfície, aquela retorna bruscamente para seu estado de equilíbrio. Conhecendo-se a constante de mola do cantilever, é possível medir as forças atrativas de interação sonda/amostra com boa precisão.

O segundo fato é sobre a elasticidade do material. Sabemos que é possível extrair informações a seu respeito estudando-se a curva de força (REBELO (2014)). Na figura, visualizamos a parte da curva de força em que a ponta está em contato constante com a amostra. Como a ponta é pressionada constantemente sobre o material, o cantilever se deflexiona. A quantidade de deflexão para uma dada quantidade de movimento descendente da sonda fornece uma indicação da elasticidade do material. Por exemplo, se o material for extremamente duro, pressionar a sonda contra ele resultará em uma quantidade relativamente grande de deflexão. Se a amostra for macia (indentável), o cantilever vai sofrer menor deflexão durante o processo de descida.

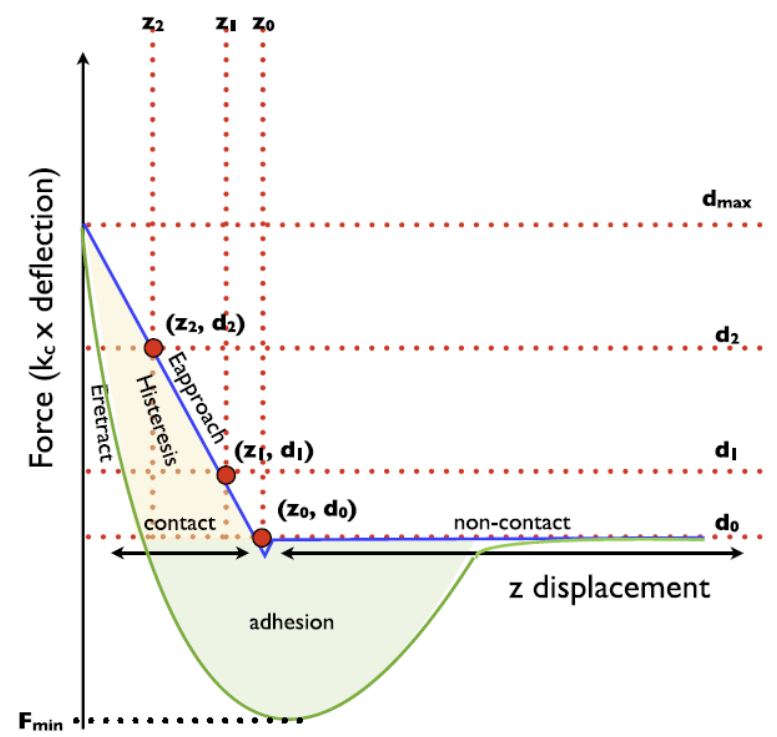

Figura 2. Figura esquemática de uma típica curva de deflexão/deslocamento adquirida com medidas de força no AFM, exibindo uma histerese entre as curvas de aproximação e retração, além de adesividade.

O formato, a inclinação e o ponto de contato da curva de força fornecem informações detalhadas sobre a elasticidade da superfície. Muitas vezes, é possível obter medidas quantitativas da elasticidade, adesividade e viscosidade da amostra como veremos nas próximas seções.

\section{MATERIAIS E MÉTODOS}

Análise das Curvas de Força: Medidas de mapeamento de força foram realizadas nesse projeto com finalidade de obter suas propriedades nanomecânicas qualitativas e quantitativas. Ensaios mecânicos são utilizados para verificar eficácia de encapsulamento (FIEL (2011)) de fármacos em nanopartículas poliméricas e lipídicas, por exemplo, além de correlacionar suas propriedades nanomecânicas com sua nanoestrutura.

Para a análise do módulo elástico das curvas de força, consideramos a teoria de contato de Hertz, cuja relação forçaindentação para um indentador cônico, (RADMACHER (2007), RADMACHER (1997) e SANTOS (2012)), é dada por: 


$$
F_{\text {cone }}=\frac{2}{\pi} \frac{E}{1-v^{2}} \tan \theta \delta^{2}
$$

onde $E$ e $\nu$ representam o módulo de elasticidade e a razão de Poisson do material, respectivamente. As amostras serão consideradas virtualmente incompreensíveis se a razão de Poisson é tomada pelo valor de 0.5 .

A quantidade $\theta$ representa o ângulo de abertura da ponta cônica. A expressão acima será usada para fitar os dados experimentais das curvas de $(z, d)$, com o objetivo de extrair, a partir delas o módulo elástico $\mathrm{E}$.

Medidas Magnéticas via AFM: As amostras de nanopartículas e nanoestruturas de carbono foram avaliadas também pelas técnicas de MFM (Magnetic Force Microscopy). Essa técnica permite a obtenção das imagens de amostras magnéticas devido às interações de longo alcance.

Neste método, o cantilever vibra com o auxílio de um suporte de ponta específico (tipholder), que contém um piezo próprio e o faz vibrar com frequência próxima a sua de ressonância. Esta frequência se altera pela resposta de uma força gradiente adicional. As forças atrativas tornam o cantilever efetivamente mais macio, reduzindo a frequência de ressonância, enquanto que forças repulsivas o tornam efetivamente mais duros, aumentando sua frequência.

A técnica MFM é uma técnica de dupla varredura, na qual a primeira varredura é realizada em modo tapping, obtendo assim dados sobre a topografia, e a segunda, realizada como um retraço da imagem de altura, porém a uma distância $\mathrm{h}$ constante entre a sonda e a superfície analisada, aquela oscilando a uma frequência de ressonância $\omega_{0}$. 0 sinal de MFM é a diferença de fase entre a força que atua entre a ponta e a amostra e a oscilação do cantilever.

Para as análises dos pontos quâticos de grafenso (GQDs, do inglês graphene quantum dots), os experimentos de microscopia de força Atômica (AFM) foram realizados com o equipamento Multimode 8 (Bruker, Santa Bárbara) utilizando o Software Nanoscope 1.50 (Bruker) no modo tapping (contato intermitente) para aquisição de imagens topográficas e de fase para determinação do diâmetro, altura e composição de fase das partículas. As experiências foram realizadas com uma constante de mola em cantilever de 0,42 N / $\mathrm{m}$ e um raio de ponta nominal de $2 \mathrm{~nm}$. As soluções de partículas foram diluídas para uma concentração de aproximadamente 109 a 1010 partículas por $1 \mathrm{~cm}^{3}$. As soluções foram depositadas em mica previamente clivada e deixadas a secar numa câmara de vácuo protegida de contaminação. 0 experimento foi realizado com uma resolução de varredura de $256 \times 256$ linhas e uma frequência de $0,5 \mathrm{~Hz}$.

As imagens de microscopia de força magnética (MFM) foram realizadas utilizando o mesmo equipamento no modo Tapping/Lifting, com elevação de 25-50 nm, utilizando sondas modelo MESP, com revestimento magnético e $\mathrm{k}$ nominal: $1-5 \mathrm{~N} / \mathrm{m}$.

Medidas de AFM topográficas de sílica mesoporosa foram realizadas com o mesmo equipamento no modo QNM usando sondas modelo SCANASYST-AIR, com constante de mola nominal de $0,4 \mathrm{~N} / \mathrm{m}$ e rádio de ponta nominal de $2 \mathrm{~nm}$ aproximadamente.

A amostra foi diluída em água pura e $10 \mu \mathrm{L}$ da solução contendo as nanopartículas de sílica mesoporosa foram depositados em mica recém-clivada. Após a secagem, a amostra foi levada para o AFM para análise. Importante o fato de que as nanopartículas foram submetidas a um preparo, onde foram dopadas de Dacarbazina (antineoplásico), marcadas com Tecnécio metaestável (99mTc), e inseridas de magnetita $\left(\mathrm{Fe}_{3} \mathrm{O}_{4}\right)$.

\section{RESULTADOS E DISCUSSÃO}

Medidas de AFM topográficas de sílica mesoporosa revelam estruturas de aproximadamente $50-90 \mathrm{~nm}$ de diâmetro, como mostrado no Fig. 3. Observamos texturas na superfície das nanopartículas, compatíveis com os mesoporos, e tais nanopartículas sempre se apresentavam agrupadas, característica associada com seu comportamento magnético.
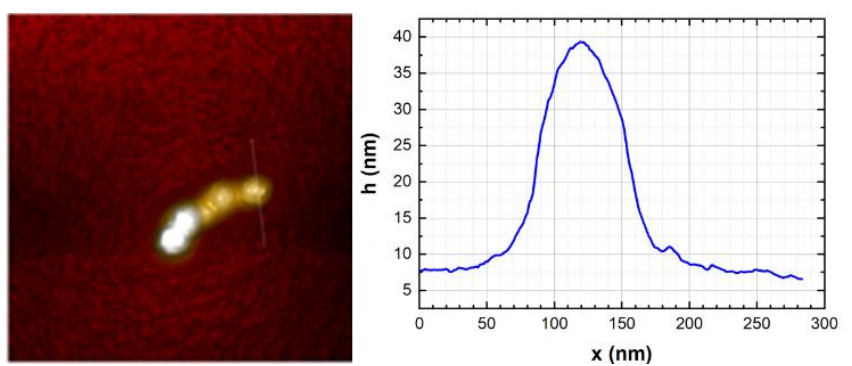

Figura 3. Esquerda: imagem de altura de AFM de agrupamento de quatro nanopartículas de sílica mesoporosa e direita: seção transversal da nanopartículas indicada na figura da direta mostrando diâmetro de $72 \mathrm{~nm}$.

Nas imagens de propriedades mecânicas obtidas no modo Quantitative Nanomechanics Peak Force (QNM), os poros dentro dos quais o material magnético está inserido ficam ainda mais evidentes, como pode ser observado na Fig. 4.

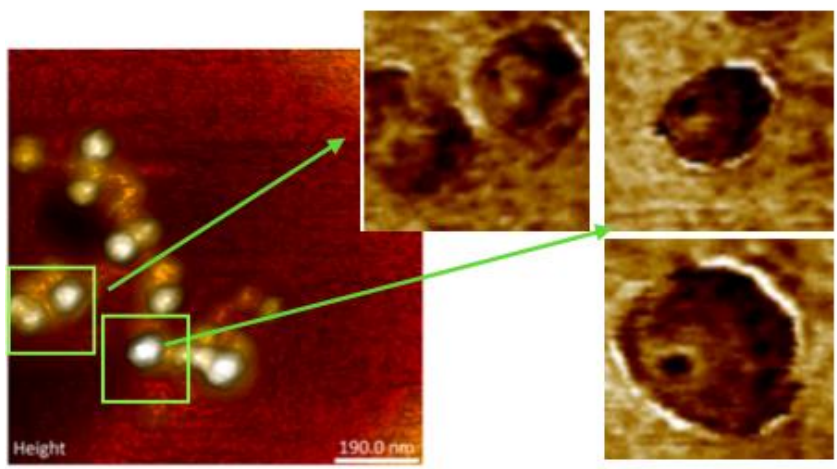

Figura 4. Imagem de altura de agrupamento de nanopartículas de sílica mesoporosa. Os quadros em verde indicam as respectivas nanopartículas que evidenciamos as imagens de adesão nos detalhes.Imagens de adesão evidenciando os poros na superfície das nanoesteruturas.

O agrupamento das nanopartículas é um dos indícios do caráter magnético desse material, no entanto, para comprovar que dentro dos poros de fato foram inseridos material magnético de tal forma que a nanopartículas assuma esse caráter, medidas de MFM foram realizadas. A Fig. 5 mostra a imagem de altura (esquerda) e MFM (direita) respectivamente dessa amostra. Nota-se que, mesmo para uma altura relativamente grande em nanoescala $(50 \mathrm{~nm})$, o contraste magnético é evidente para região dos poros, especialmente (setas verdes), confirmando que, de fato, as nanoestreuturas são magnéticas em nanoescala.

Para os GQDs, os resultados da microscopia de força atômica (AFM) são mostrados na Fig. 6. De acordo com a análise dos dados, o diâmetro médio dos GQDs variou no intervalo de 160-280 nm, enquanto as alturas mais freqüentes foram de cerca de $5 \mathrm{~nm}$. A rugosidade foi muito baixa, com um Rq de 4,58nm e Ra de 3,42nm. Esses resultados são essenciais pois, especialmente para estruturas de grafeno, a informação de altura é extremamente importante. 

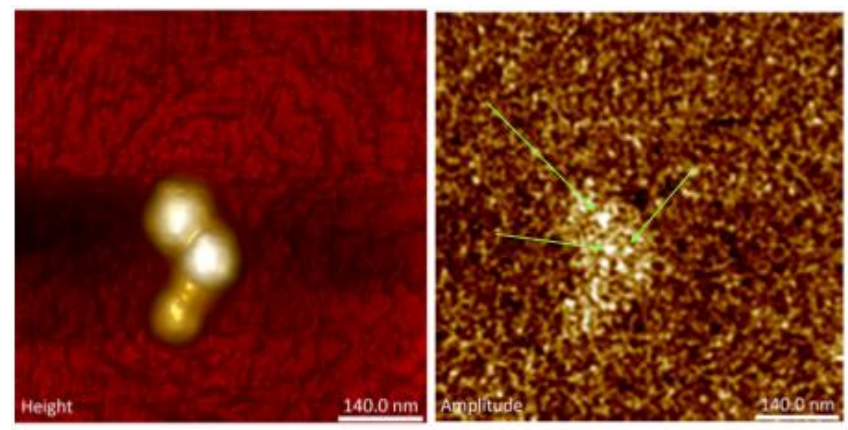

Figura 5.Imagem de altura (esquerda) e MFM (direita) de nanopartículas de sílica mesoporosa. As setas verdes indicam regiões onde o material magnético está inserido nos poros.
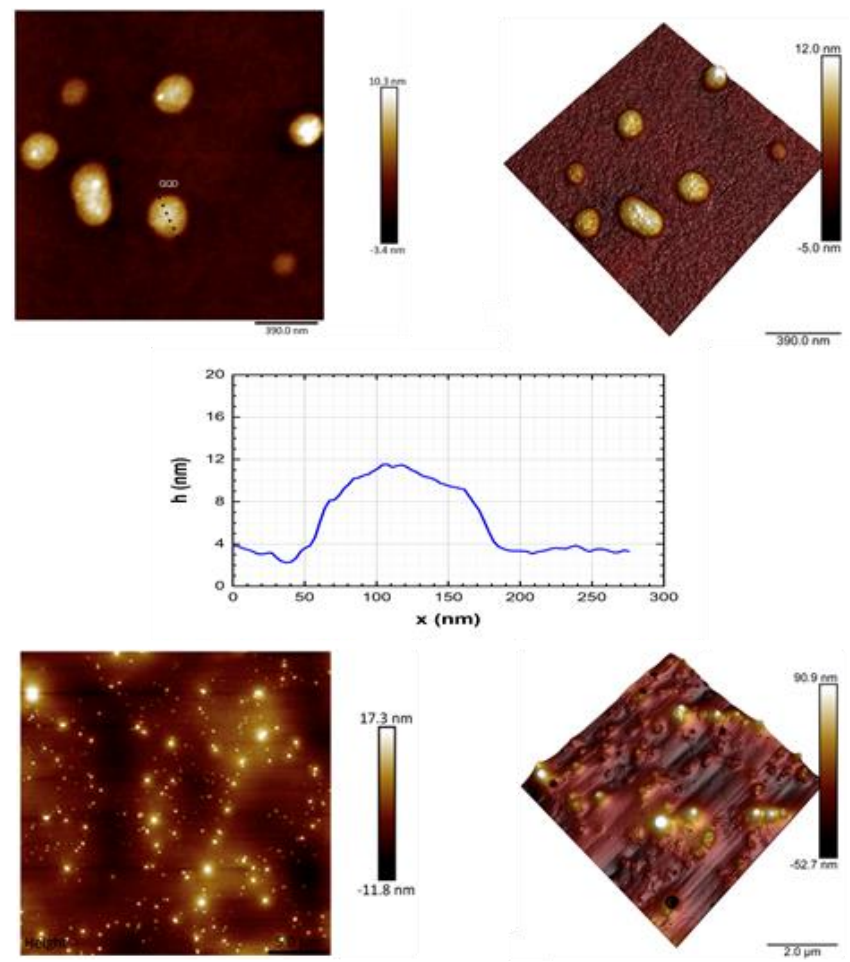

Figura 6. Análise microscópica da força atômica dos pontos quânticos do grafeno. Imagens superiores apresentam GQDs com distribuições de tamanho de 160-280 nm e visualização 3D revelando perfil de grafeno, também destacado em seção transversal (meio). As imagens de baixo apresentam uma visão geral de muitos GQDs, permitindo confirmar a distribuição do tamanho de partículas com o software do AFM.

\section{CONCLUSÕES}

As imagens topográficas de AFM revelaram nanopartículas de sílica mesoporosa com diâmetros de aproximadamente 60-90 nm. A superfície das partículas tem textura compatível com os poros de sílica. As imagens de adesão mostraram contraste diferenciado de adesão na superfície da nanopartícula de sílica quando comparado ao substrato de mica. Nas imagens de adesão, o caráter poroso da sílica também é observado, com locais de adesão diferenciada, mesmo na superfície de uma partícula individual. As imagens de microscopia de força magnética mostraram contraste magnético em imagens de amplitude com $50 \mathrm{~nm}$ de elevação. Observa-se que o contraste magnético não está em toda a área que contém a partícula, sendo compatível com o fato de que o material magnético penetra apenas alguns poros da sílica, provavelmente correlacionado com regiões internas da sílica onde há mais material magnetita. A altura de elevação utilizada foi de $50 \mathrm{~nm}$ acima da superfície das nanopartículas. Em alturas mais elevadas, o contraste magnético foi extremamente pobre, provavelmente devido à baixa concentração de material magnético dentro de uma partícula nanométrica. Nesta escala de tamanho, observamos superparamagnetismo, dificultando o sinal no modo MFM. Em todas as imagens de AFM, observamos as partículas agrupadas mesmo em baixas concentrações. Este fato pode estar relacionado ao caráter magnético das nanopartículas.

Em relação aos GQDs, a microscopia de força atômica foi fundamental para mostrar a altura e diâmetro das ilhas de grafeno desse pontos quânticos e para realização de estatística de distribuição de tamanho e rugosidade de superfície, uma vez que ainda observa-se a presença se alguns reagentes da rota se síntese na superfície do mesmo, como citrato, por exemplo.

\section{REFERÊNCIAS}

Alessandrini, Andrea, \& Facci, Paolo. 2005. AFM: a versatile tool in biophysics. Measurement Science and Technology, 16(6), R65.

C. B. Prater, P. G. Maivald, K. J. Kjoller M. G. Heaton. 1995. Probing Nanoscale forces with an Atomic Force Microscope. Thecnical Notes Veeco - AN08 10/95.

do Nascimento, R. O. et al. 2017. Physicochemical Characterizations of Nanoparticles Used for Bioenergy and Biofuel Production. 1a edn. Nanotechnology for Bioenergy and Biofuel Production., vol. 1. Springer.

Fiel, L. A. et al. 2011. Diverse deformation properties of polymeric nanocapsules and lipid-core nanocapsules. Soft Matter., 7(1), 72407247.

Kuznetsova T. G., Starodubtseva M. N., Yegorenkov N. I. Chizhik S. A. Zhdanov R. I. 2007. Atomic force microscopy probing of cell elasticity. 38, 824-833.

Radmacher, M. 1997. Measuring the elastic properties of biological samples with the AFM. IEEE Eng. Med. Biol. Mag., 2(16), 47-57.

Radmacher, M. 2007. Studying the Mechanics of Cellular Processes by Atomic Force Microscopy. Methods in Cell Biology. Cell Mechanics., 83, 347-342.

Rebelo, L. M. et al. 2014. Correlating cell morphology and viscoelasticity to investigate diseases with atomic force microscopy. Chap. Scanning Probe Microscopy, pages 141-152 of: Méndez-Villa, A. (ed), Microscopy: advances in scientific research and education, vol. 1. Spain: FORMATEX - Microscopy Series no 6.

Rebelo, L.M. 2010. Estudo da viscoelasticidade de células de câncer renal por microscopia de for ,ca atômica. Tese (Doutorado em Física), Universidade Federal do Ceará, Fortaleza.

Santos, J. A. C. et al. 2012. Thickness-corrected model for nanoindentation of thin films with conical indenters. Soft Matter., 8(16), 4441-4448.

V. J. Morris, A. R. Kirby, A. P. Gunning. 2009. Atomic Force Microscopy for Biologists. 2a edn. Imperial College Press.

Zanette, S. I. 2010. Introdução à Micropscopia de Força Atômica. 1a edn. Vol. 1. Oxford. 